\title{
KOLUMBUS: Context-oriented communication support in a collaborative learning environment
}

\author{
Thomas Herrmann and Andrea Kienle \\ Informatics \& Society, University of Dortmund, D-44221, Dortmund, Germany
}

\{thomas.herrmann; andrea.kienle\}@udo.edu

Key words: Collaborative Learning, Communication, Learning Environments

\begin{abstract}
Computer supported collaborative learning occurs primarily by means of communication. Successful computer supported co-operation is only possible if communication among learners and between learners and teachers is appropriately supported. We describe communication on the basis of a context-oriented communication model that focuses on the dialogical communication and mediation of context. The model leads to an abstract identification of general communication tasks amongst collaborating learners and between them and their teachers. The resulting list of tasks can be generally used to derive requirements for the support of communication in collaborative learning environments. This is demonstrated with the features of the prototype system "KOLUMBUS", which is used for experimental investigation in university courses. It realises the support of all identified communication tasks. The paper ends with a brief summary of results taken from experiences at a university seminar as part of a larger research work.
\end{abstract}

\section{INTRODUCTION}

An increasing number of developments can be assigned to the paradigm of computer supported collaborative learning (CSCL). The most important concept of collaborative learning is the active role of the learner and Koschmann (1996) and Wiburg (1995) recognised a paradigm shift in this development towards a self-responsible learner.

The original version of this chapter was revised: The copyright line was incorrect. This has been corrected. The Erratum to this chapter is available at DOI: 10.1007/978-0-387-35663-1_34 
For CSCL-Systems, the support of interaction is mostly focused on communication. Rather than directly experiencing a situation or learning by observing learners interact at different locations and during different time slots. Appropriate methods which support communication among learners and between learners and teachers are decisive factors in the success of collaborative learning environments. In the past the area of support for communication was insufficiently investigated.

To improve CSCL environments we focus on those types of communication theory where communication is understood to be symbolic interaction between identifiable persons who can be directly addressed in the course of dialogues. The mass distribution of instructions (as part of an expression) is not included in this perspective if there is no opportunity for learners to realise their success in learning and achieve mutual understanding through the process of social interaction.

We have developed a prototype system called KOLUMBUS which is strictly oriented towards the support of interactive, mainly asynchronous communication and the conveying of the context which completes the communication processes. This idea of strict orientation to communication support was inspired by the experience with other CSCL systems. BSCW Shared Workspace System (Appelt and Mambrey 1999) allows easy upload of documents, however, the presentation of content takes place in the system in which they were developed e.g. Microsoft Word. Furthermore, communication is not sufficiently supported in this system as it occurs outside the workspace. CSILE (Computer Supported Intentional Learning Environments), on the other hand, allows all participants to add any desired information to the system and this content can be used as easily accessible context information. A disadvantage is that participants have to use html commands to add their content to the system if they wish to produce readable, pleasant presentations that foster understanding (Scardamalia and Bereiter 1996). Gentle, allows readable versions of content to be produced which can then be annotated but it is neither possible to limit the group of recipients nor to extend the set of responsible authors (Dietinger and Maurer 1998). In WebGuide (Stahl and Herrmann 1999), statements or annotations can be added to the content on the system. However, these contributions did not relate closely and there was a lack of convergence in discussions. We concluded that structured negotiation and the facilitation of discussions should be supported in CSCL systems.

KOLUMBUS is based on these results and is designed to improve communication-based learning in universities. The educational goal is twofold. Firstly, students should benefit from the experience of others by conducting research on a specific topic (e.g. the conditions under which the New World could be discovered by Columbus) and knowledge of these 
topics should be deepened by discourses between students. Secondly, students should learn how social learning can be conducted through the medium of computer networks under asynchronous communication conditions. This requires more explicit interaction and documentation as well as a high degree of discipline.

\section{CONTEXT-ORIENTED MODEL OF COMMUNICATION}

In computer science, models of communication are generally characterised by the sender-recipient model (Shannon and Weaver 1949). In this model the sender's message is transmitted to the recipient using a channel. The message is encoded before and decoded after the transmission. In psychologically-oriented research, however, the influence of both communication partners on the communication act and its contribution to increase shared understanding (Clark and Brennan 1991) and the relevance of context for the communication (Ungeheuer 1982) are more important. This leads to a kind of communication model which is focused on how mutual understanding can succeed in dialogues. Its origins are rooted in neoconstructivism (von Glaserfeld 1996) and biological epistemology (Maturana and Varela 1987).

Maturana and Varela in particular point out that the models where something such as information is transported from a sender to a receiver are completely inappropriate. Sender and receiver are closed systems with respect to information processing. A communicator selects from the universe of his/her beliefs what he/she wants to say and the recipient selects, with respect to his/her universe of beliefs what he/she wants to understand. These universes of beliefs may be considered a kind of inner context and this is closely related to the outer context they can share in their perception. One important part of the context is the reciprocal knowledge of the other. Our communication model is based on the assumption that only the availability of context can give the communicators a feeling of whether their communicative acts are successful not.

\subsection{Activities of the communication partners}

A communicator selects the idea which has to be represented (what) and selects the appropriate paraphrase. This means deciding how the idea has to be presented to specific recipients to be easily understood. Only then can an expression be uttered. The recipient creates a mental representation of the 
expression and transforms this representation into an impression related to the recipient's universe of beliefs. Producing an impression can only succeed if the recipient inter-relates his/her pre-knowledge with the representation of the expression. It is vital for learning that the impression is integrated into and made a relatively permanent part of this universe. Some articles deal with the fact that learners convert information into knowledge on the basis of their already existing knowledge (Feltovitch et al 1996). It is the task of both communicator and recipient to check whether the communication act was successful or has still to be completed.

Context has an important relevance for several activities of the communicator and the recipient. Remember that context combines many different aspects - the physical situation, the cultural and geographic constellation, the characteristics - especially the knowledge - of alter ego, the expressions already uttered by the participants in communication and the extra-communicative behaviour of the participants. This extracommunicative behaviour is especially important because it is independent from symbolic meanings.

The special relevance of context is seen in certain activities of a communication act.

- (Selecting what has to be communicated) By being aware of the context and by having a model of the knowledge a recipient already has, or can easily derive from the context, the communicator can decide whether it is sensible to communicate an idea for purposes such as teaching, giving an orientation or entertainment.

- (Selecting the appropriate paraphrase) The context gives hints about how explicit an expression should be. The communicator can decide whether a certain aspect of his idea has to be explicitly expressed or is evident because of the context which is shared with the recipient. Furthermore, the communicator uses the context to decide which level of language might be understood or what metaphors or comparisons are appropriate.

- (Making an impression) By relating the representation of the expression to the context, especially to the assumed knowledge of the communicator, it is easier for the recipient to find out what the communicator might have meant. Context completes the representation of the expression. Furthermore, the recipient can identify whether he/she needs additional information from the communicator or not.

- (Learning) The context can be employed to make implicit decisions on whether an impression is sufficiently relevant to be relatively permanently integrated into the universe of the recipient's beliefs.

- (Avoidance of misunderstandings) Observing the context - particularly the ongoing communication but even more importantly, the extracommunicative behaviour - develops awareness of misunderstandings. 


\section{REQUIREMENTS FOR THE SUPPORT OF COMPUTER MEDIATED COMMUNICATION}

The mutual context can be reduced during online communication compared with face-to-face communication. Only certain parts of the context of the communication partners can be mutual (knowledge of physical laws, geographic constellations). Consequently, communicators should ensure the relevant context is available for the recipient. We can differentiate between the following situations with respect to collaborative learning:

1. A teacher or a student collects material (content) for their own work. While doing so, they do not connect any communicative intentions with this material. When the teacher distributes a task description to the students, or when the student makes a proposal to his fellows, these are communicative acts. The material serves as context for these acts and is provided by the communicators themselves. They do not have to feel responsible for the communicative quality of this material.

2. Teachers or students formulate an expression and realise that their potential recipients might not have enough context at their disposal to understand what is meant. Therefore, the communicators make additional material accessible which creates the relevant context - an e-mail attachment or the inclusion of a URL. Another solution might be to insert a communicatively meant expression directly as an annotation into the material.

3. In some cases, the participants of the collaborative environment may realise that it will be difficult for the recipients of a message to combine it with the available material or that the availability of context is insufficient. They may decide not to rely on the recipients' context perception but to express the relevant parts of the context in their own words and integrate it directly into the expression. Thus, they make context explicit.

The main idea of supporting the activities of communication partners in computer mediated learning processes involves the individual and flexible presentation of content.

To note the knowledge of the recipient, the communicator can inspect, for example, a web-based collection of the recipient's information. Using links and by exploiting the free formulation of contributions, the communicator can explicitly describe the relevant context. Since it is hard to anticipate the amount of context required, it is sensible to offer possibilities for splitting the conveyed context into several parts that can be selected flexibly by the recipient. Hide and show mechanisms are excellent for 
concealing unimportant aspects. Table 1 summarises the activities of the communicator and the software components of KOLUMBUS.

Table 1. Support for the activities of the communicator

\begin{tabular}{ll}
\hline Activities of communicators & Software components in KOLUMBUS \\
\hline Being aware of the knowledge of & $\begin{array}{l}\text { Offering perspective where information can be browsed } \\
\text { related to the recipient and available in the system. } \\
\text { Support of browsing this information by meta- } \\
\text { information, search, rating and filter mechanisms and } \\
\text { awareness features. }\end{array}$ \\
& $\begin{array}{l}\text { Offering possibility to annotate communicative } \\
\text { contributions directly to those parts of content to which } \\
\text { they are related. }\end{array}$ \\
Making context available & $\begin{array}{l}\text { Adding links to messages which refer to context. } \\
\text { Offering means to support segmentation of content into }\end{array}$ \\
small items. \\
Sumport divisibility of content by hide and show \\
concealing unimportant aspects & $\begin{array}{l}\text { mechanisms based on means for segmentation and tree } \\
\text { views. }\end{array}$ \\
Compensating for the reduced & $\begin{array}{l}\text { Multimedia based possibilities of representing different } \\
\text { layouts of content. }\end{array}$ \\
possibilities of expressions & Different communication channels e.g. chat. \\
\hline
\end{tabular}

The recipient can use his own collection of information to relate the expression to his/her own knowledge and the collection of the communicator to note his knowledge. All the components mentioned in Table 1 are important for the recipient.

Awareness features support the identification of the mediated context. To reconstruct the context, easy access to documents is needed. To support requests for further information support for interactivity has to be offered.

\section{THE COLLABORATIVE LEARNING ENVIRONMENT KOLUMBUS}

The aim of KOLUMBUS is to provide optimal integration of context presentation and support of communication by offering all the above components. Figure 1 shows a process-oriented view of the KOLUMBUS features and their interrelation. 


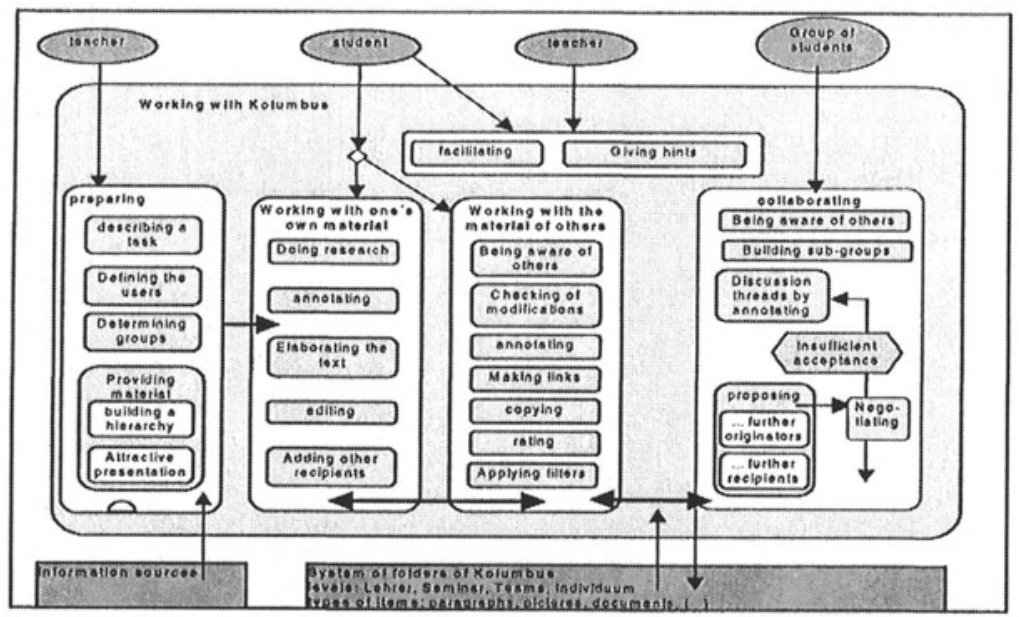

Figure 1. Usage process using the modelling method SeeMe

\subsection{Preparing and working with one's own material}

A lecturer prepares a seminar by describing a task, determining who has to participate and identifying how these participants may be grouped. KOLUMBUS facilitates the flexible presentation of content, offers two kinds of views of the content and permits its easy upload.

Students build up and improve their own material by collecting, annotating and editing. This can be enhanced by the exchange of information fostering collaborative working.

The central feature of KOLUMBUS is the representation of content in small units which enables students to use the stored content very flexibly. The smallest unit, or item, can be a text, picture, binary number, link or annotation. The content can be presented as a hierarchical structure of items viewable in a web-browser. Items can be inserted at any level of the hierarchy and the teacher, as well as the students, can build a hierarchy of their material. All existing functions (annotate, rate, copy, shift, change) can be applied to every item.

The system provides two different views of content. In treeview each item is represented as a node in a hierarchical tree-structure (Figure 2) whereas paperview illustrates the content in a more visually attractive and readable way. Different types of presentations can be combined to form a single document. In paperview it is possible to expand or omit content of every item, and all functions are available. Uploading content is easy - no HTML knowledge is necessary. The menu providing access to the system's 
functions is bound to items so further items may be added at the place from which the participant called the menu.

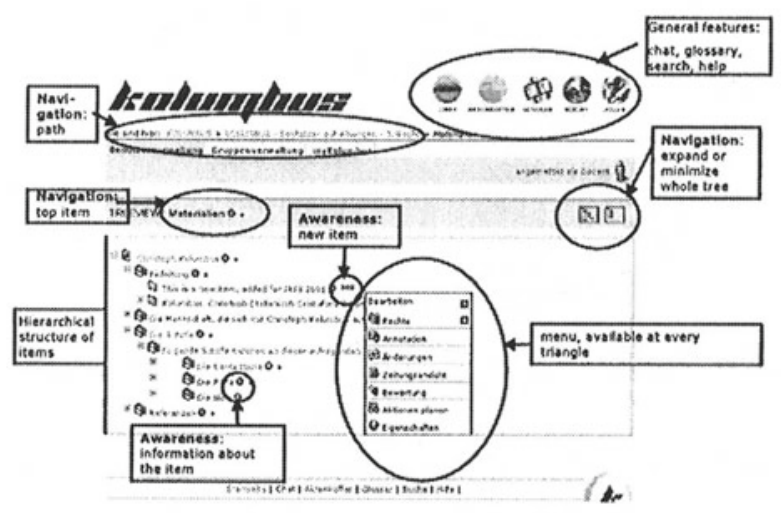

Figure 2. KOLUMBUS - a treeview

As it is necessary to disperse longer content into many items to enable the flexible presentation and use of the content, we have developed two main ways of adding content. On the basis of a DTD, an XML-document can be dispersed into single items and using a predefined Microsoft Word template an XML-document (whose titles, sections or tables are recognized as KOLUMBUS items) may be created.

\subsection{Working with the material of others}

Students can identify and check new or modified items and be aware of other's activities by using the awareness features (meta-information, search, rating and filter). In the treeview, new and modified items can be recognized.

Search functionality is provided. A communicator might use this to identify the knowledge of the recipient and a recipient might use it when including knowledge or reconstructing the context. Searching for "annotation" retrieves all contributions to discussions. A rating function allows users to give feedback and a filter restricts the visible items to the chosen group of authors and/or recipients.

Using the annotation function participants give feedback on others' materials. The concept of items enables them to annotate directly in the content and makes the context explicit. Discussion threads are developed by annotating annotations. KOLUMBUS also offers synchronous communication through the chat function - extremely valuable for requesting further information. 
To support the collaborative process of learning, a concept of different perspectives is realized. In KOLUMBUS, a perspective is defined by three characteristics: its content, the set of originators responsible for the content and the set of recipients. Extending the group of recipients allows an originator to publish his content to others.

\subsection{Collaborating}

Group results are developed by the process of taking responsibility for certain items. The originator initiates a negotiation by proposing further originators. The proposed originators vote for or against their originatorship for the item in question and if a certain percentage agrees with the proposal, the group of originators will be extended. Thus the group achieves convergence on a certain set of items. If a group of students is the originator of an item and a single person wants to extend the group of recipients, the group members also have to negotiate the proposition of further recipients. Every participant can be aware of the progress of the collaborative learning process; a request for a negotiation for example shows a concluding step in the process.

\section{CONCLUSION: FIRST EXPERIENCES}

Since April 2001 we have tested KOLUMBUS in a seminar environment with 16 students. Its use was evaluated through interviews and the analysis of logfiles.

The possibility of observing others' material and their usage of the system was considered extremely helpful in fulfilling personal tasks. The concept of annotations was highly accepted to support the communication during the feedback process. Students added annotations to singles items and confirmed they used existing content as context information that did not have to be explicated again. As recipients of annotations they indicated understanding was improved by reading the content and the annotation at the same time.

Some students described problems finding the annotations. Awareness features like "new" tag were not sufficient. Students suggested a list of new items should be displayed on the top screen immediately after login or an email notification. They also requested a feature for displaying all annotations to their material in a single view. Further research is necessary to find out how features of KOLUMBUS, which seem to be too general, should be specified to reflect the underlying scenario. 
Despite these shortcomings, our evaluation concluded that the integration of context presentation and support of communication offered by KOLUMBUS improved communication-based learning.

\section{REFERENCES}

Appelt, W. and Mambrey, P. (1999) Experiences with the BSCW Shared Workspace System as the Backbone of a Virtual Learning Environment for Students. In Proceedings of ED Media '99, Charlottesville. pp. 1710-1715.

Clark, H. H. and Brennan, S. E. (1991) Grounding in Communication. In Resnick, L. B., Levine, J. M and Teasley, S. D., Perspectives on Socially Shared Cognition. American Psychological Association, Washington, DC. pp. 127-149.

Dietinger, T. and Maurer, H. (1998) GENTLE - General Network Training and Learning Environment. In Proceedings of the Ed-Media 1998, Freiburg.

Feltovich, P. J., Spiro, R. J., Coulson, R. L. and Feltovich, J. (1996) Collaborative Within and Among Minds: Mastering Complexity, Individually and in Groups. In CSCL: Theory and Practice, T. Koschmann, (ed.), Lawrence Erlbaum Associates, New Jersey. pp. 25-44.

Glasersfeld, von (1996) Radikaler Konstruktivismus. Suhrkamp, Frankfurt am Main.

Koschmann, T. (ed.) (1996) CSCL: Theory and Practice, Lawrence Erlbaum Associates. New Jersey.

Maturana, H. and Varela, F. (1987) Der Baum der Erkenntnis. Scherz. Bern, München, Wien.

Scardamalia, M. and Bereiter, C. (1996) Student Communities for the Advancement of Knowledge. In Communications of the ACM, Vol. 39, No. 1. pp. 36-37.

Shannon, C. E. and Weaver, W. (1949) The Mathematical Theory of Communication, The University of Illinois, Urbana (Illinois).

Stahl, G. and Herrmann, T. (1999) Intertwining Perspectives and Negotiation. In Proceedings of Group'99 International conference on Supporting Group Work. Phoenix, Arizona. pp. 316-325.

Ungeheuer, G. (1982) Vor-Urteile über Sprechen, Mitteilen, Verstehen. In Kommunkationstheoretische Schriften 1, G. Ungeheuer (ed.), Rader, Aachen. pp. 229-338.

Wiburg, K. M. (1995) An Historical Perpective on Instructional Design: Is it Time to Exchange Skinner's Teaching machine for Dewey's Toolbox? In Proceedings of the First International Conference on Computer Support for Collaborative Learning (CSCL '95), J. L. Schnase, and E. L. Cunnius (eds.). pp. 385-391. 